Revista de

Contabilidade e

Organizações

www.rco.usp.br
DOI: http://dx.doi.org/10.11606/issn.1982-6486.rco.2019.144691

Journal of

Accounting and

Organizations

\title{
Efeitos da rotatividade de pessoal sobre práticas das equipes de contabilidade em municípios
}

The effects of turnover on accountants' practices in Brazilian local governments

Ricardo Rocha de Azevedo ; André Feliciano Lino ${ }^{\mathrm{b}}$; Josedilton Alves Diniz ${ }^{\mathrm{c}}$

${ }^{a}$ Universidade Federal de Uberlândia

${ }^{b}$ Universidade Federal do Pará

${ }^{c}$ Universidade Federal da Paraiba

Palavras-chave

Rotatividade.

Municípios.

Reforma contábil.

Institucionalização.
Keywords

Turnover.

Municipalities.

Accounting reform.

Institutionalization.
Informações do Artigo

Recebido: 24 de março de 2018

Aceito: 22 de abril de 2019

Publicado: 26 de abril de 2019

\section{Resumo}

$\overline{\mathrm{O}}$ artigo discute os efeitos da rotatividade de equipes de contabilidade sobre a execução e adoção de práticas executadas por esta equipe em cerca de 2.800 prefeituras brasileiras. Para tal, foram estimados três modelos quantitativos em que a execução de práticas pela equipe de contabilidade (com diferentes graus de complexidade) foi analisada em função da rotatividade de servidores de departamentos de contabilidade. Verificou-se que a rotatividade de equipes de contabilidade nas prefeituras (i) está associada com a troca dos prefeitos; e, (ii) impacta negativamente a execução e adoção de práticas complexas, contudo, o efeito é inverso quando as práticas são consideradas simples. $\mathrm{O}$ artigo contribui ao diminuir a significativa falta de evidenciação empírica sobre a rotatividade de cargos técnico-burocráticos, que supostamente seriam predominantemente posições estáveis nas organizações do setor público brasileiro. No contexto da reforma da contabilidade aplicada ao setor público, o artigo discute e traz implicações para a organização dos municípios, órgãos normatizadores e Tribunais de Contas.

\begin{abstract}
We explore the effects of turnover on the execution and adoption of practices executed by accountants in approximately 2,800 Brazilian municipalities. We developed three quantitative models in which turnover affect practices with different degrees of complexity. We find that accountants' turnover in municipalities is (i) associated with the change of mayors; and (ii) negatively impacts the execution and adoption of complex accounting practices; however, the opposite occurs when practices are simple. The article contributes reducing the lack of empirical evidence on the turnover of technical-bureaucratic positions, allegedly tenured in the Brazilian public sector organizations. In the context of public sector accounting reform, the article discusses and present implications for the internal organization of municipalities, and the role of standard setters and Courts of Accounts.
\end{abstract}

\section{Implicações práticas}

As demandas da contabilidade pública são cada vez maiores. Municípios devem estar atentos ao processo de seleção e composição de suas equipes de contabilidade. Órgãos normatizadores, por sua vez, deveriam realizar capacitações buscando mitigar os efeitos negativos da rotatividade de servidores e enfatizar seus aspectos positivos.

Copyright (C) 2019 FEA-RP/USP. Todos os direitos reservados

\section{INTRODUÇÃO}

A realização de tarefas em organizações depende, ao menos em parte, das qualificações técnicas e experiência dos membros da equipe que a executam (Carley, 1992; Price, 1977). Dessa forma, a rotatividade de pessoal impactaria a execução e o desempenho de tarefas organizacionais (Meier \& Hicklin, 2008). No setor público, a questão da rotatividade vem sendo associada aos seus líderes, ou seja, a natural troca de governantes eleitos e indicação de cargos de confiança - essenciais para a governabilidade em um sistema de presidencialismo de coalizão (Bertholini \& Pereira, 2017; Lopez, Bugarin, \& Bugarin, 2015; Schedler \& Santiso, 1998; Spink, 1987). 
Esta dinâmica pode levar a descontinuidade administrativa, caracterizada por políticas - ou, até mesmo organizações - que perdem prioridade na agenda, tem seus objetivos alterados ou, no limite, são interrompidas (Nogueira, 2006). Contudo, a literatura não trata a rotatividade, ou troca, de pessoal que ocorreria além das posições eletivas e de direção e assessoramento no setor público brasileiro. Esse é um ponto relevante a ser estudado, dado que as equipes técnico-burocráticas, supostamente estáveis, são responsáveis pela execução de diversas políticas em municípios (Cavalcante, Lotta, \& Oliveira, 2018), além de diversas atividades meio. Por exemplo, as rotinas contábeis seriam executadas por contadores concursados na Secretaria da Fazenda.

Além disso, os estudos sobre rotatividade habitualmente tratam dos seus efeitos sobre práticas em uso, desconsiderando seu grau de institucionalização, ou seja, a ampla aceitação das práticas sendo vistas como adequadas e necessárias para uma dada organização (Tolbert \& Zucker, 1983). O artigo utiliza conceitos institucionais para complementar a abordagem de aprendizagem organizacional, como sugerido por Haunschild e Chandler (2008). A alta troca de pessoas e de líderes aumenta a diversidade da força de trabalho gerando a possibilidade de institucionalização apenas de forma incompleta, o que tende a impedir a continuidade de práticas organizacionais (DiMaggio, 1988; Oliver, 1992). Ou seja, existiriam ciclos constantes de adoção de novas práticas, porém nunca mantidas no longo prazo.

Devido à estabilidade no setor público brasileiro, tem-se a impressão de que não acontece troca de pessoal nas equipes da camada burocrática no setor público. Este artigo desafia esta visão generalizada de que a rotatividade acontece apenas entre seus governantes e em posições de direção e assessoramento. Para isso, avaliamos práticas executadas pela equipe de contabilidade ainda não institucionalizadas em municípios brasileiros. Muito embora algumas práticas sejam passíveis de automatização (Azevedo et al., 2017), existe grande dependência dos contadores em relação a outras práticas menos automatizáveis. Conforme a visão de aprendizagem organizacional, complementada pela teoria institucional, a rotatividade de pessoal impactaria a execução de práticas vigentes e adoção de novas práticas executadas pela burocracia contábil. Assim, o artigo analisou a troca das equipes de contabilidade e qual seu impacto na execução e adoção de práticas executadas por tais equipes em prefeituras brasileiras.

Primeiramente, o artigo verificou se existia associação entre a descontinuidade política (troca do prefeito) com a troca da equipe técnica de contabilidade em municípios. Em seguida analisou a existência de efeitos da troca dessas equipes de contabilidade sobre as práticas (não institucionalizadas) que elas executam. $\mathrm{O}$ artigo contribui mostrando que os impactos da rotatividade dependem do grau de complexidade das diferentes práticas executadas pelas equipes de contabilidade.

\section{MODELO CONCEITUAL E DESENVOLVIMENTO DE HIPÓTESES}

O desempenho de organizações ou equipes depende das capacidades e experiência de seus membros individuais, de forma que a rotatividade de pessoal pode impactar a execução de práticas em organizações (Carley, 1992; Haunschild \& Chandler, 2008). O impacto pode ser tanto negativo, pela saída de funcionários sem que haja um mecanismo para a transferência de conhecimento inerente ao capital humano, quanto positivo, quando novas habilidades são adquiridas com a chegada de novas pessoas (Price, 1977).

Buscando racionalizar a discussão, Meier e Hicklin (2008) afirmam que o efeito da rotatividade de pessoal sobre a execução de práticas no setor público está relacionado ao grau de dificuldade das tarefas executadas. Os autores demonstram que existe um efeito linear negativo da rotatividade em práticas com baixo grau de dificuldade. Porém, quando o grau de dificuldade na execução das tarefas aumenta, a rotatividade produz um efeito U invertido que será positivo até um certo ponto e depois passa a ser negativo.

Entretanto, os autores negligenciam o fato de que algumas práticas podem ser adotadas por organizações sem que estejam completamente legitimadas ou aceitas socialmente (Tolbert \& Zucker, 1983). Isso implica que algumas práticas fazem parte de determinada estrutura formal de organizações, porém podem não estar institucionalizadas. Tais práticas institucionalizadas são aquelas amplamente aceitas e vistas como apropriadas e necessárias para a função exercida pela organização (Tolbert \& Zucker, 1983). O grau de institucionalização da prática é algo relevante e não discutido quando se trata dos impactos da rotatividade de pessoas sobre organizações. Assim, é útil para estas análises combinar elementos da teoria institucional com a perspectiva dominante da literatura em rotatividade de pessoas e aprendizagem organizacional (Haunschild \& Chandler, 2008).

Organizações como prefeituras operam em um campo organizacional - que dá o contexto no qual as suas atividades executadas ganham significado e estão inseridas (Scott, 2014). Portanto, as operações e práticas nas prefeituras estão sujeitas às influências institucionais deste campo. 
O campo organizacional da contabilidade pública brasileira tem sido marcado por um constante movimento de reformas, no mínimo desde 2008, com uma agenda voltada à introdução de normas internacionais International Public Sector Accounting Standards (IPSAS) (Azevedo et al., 2017). Tal reforma torna compulsória a adoção de práticas em municípios que não estão institucionalizadas. Conforme Azevedo (2016), os profissionais de contabilidade que desempenham suas atribuições segundo a estrutura formal designada por municípios podem não aceitar os novos padrões das reformas e acabam resistindo à adoção dessas práticas. Segundo Diniz et al. (2015), até mesmo entre os membros do grupo de normatização do setor público no Brasil existe divergência quanto à possibilidade de convergência total às IPSAS. Divergências em relação à adequação e pertinência das novas práticas é uma característica que gera resistência no processo de difusão e aceitação dessas práticas (Oliver, 1991).

Além disso, o setor público, especialmente em democracias presidencialistas, é caracterizado pela constante troca de governantes e consequentemente de posições em cargos comissionados de diretoria e assessoramento (Lopez et al., 2015; Schedler \& Santiso, 1998; Spink, 1987). A constante troca de pessoas levaria à institucionalização incompleta de práticas - ou seja, a tendência de que práticas sejam seguidas por um curto período, até que a sua fonte de apoio seja extinta (DiMaggio, 1988). Na prática, isso se materializaria em um Secretário da Fazenda e/ou contador-chefe que não vê importância na adoção de determinadas práticas contábeis específicas. Como a troca de governantes no setor público é caracterizada por marcos de gestão que diferenciam um governo de outro e por vezes gera descontinuidade administrativa (Nogueira, 2006), seria natural esperar que a cada novo ciclo novas práticas fossem priorizadas, haja vista que a alta troca de pessoas nas equipes e de líderes aumenta a diversidade da força de trabalho e tende a impedir a continuidade de práticas organizacionais (Oliver, 1992). Em resumo, a rotatividade de pessoal impactaria de forma negativa a execução e adoção de práticas não institucionalizadas em organizações, incluindo práticas executadas pelas equipes de contabilidade.

Contudo, a rotatividade produziria efeitos positivos, pois, os novos servidores podem ser mais reflexivos, inovadores, eficientes e menos resistentes às mudanças organizacionais (Greenwood \& Hinings, 1996). A melhor capacidade de solução de problemas destes atores é vista como fundamental em tarefas com maior grau de complexidade. A complexidade da tarefa não é composta apenas pela sua dificuldade, como já tratado em Meier e Hicklin (2008), mas também do grau em que diversos atores são conectados e devem ser coordenados para executá-la (Andrews \& Boyne, 2014). Nesse sentido, tarefas complexas demandam não só capital de recursos manifestado na capacidade técnica dos novos servidores e no tamanho da equipe, mas também capital institucional - que se materializa na capacidade de mobilizar apoio à execução de determinadas práticas junto à atores diversos dentro ou fora da organização (Oliver, 1997). Em tarefas menos complexas, por sua vez, o menor requerimento por recursos e capital institucional levaria a um maior efeito da reflexividade dos novos atores que entram na organização, de forma que a rotatividade de pessoal seria positiva para a execução de tarefas e desempenho da organização. Assim, sugerimos a seguinte hipótese de pesquisa:

$\mathbf{H}_{1}$ : A rotatividade das equipes impacta negativamente a execução das práticas organizacionais não institucionalizadas e com alto grau de complexidade $\left(\mathrm{H}_{1 \mathrm{a}}\right)$ e positivamente a execução das práticas não institucionalizadas e com baixo grau de complexidade $\left(\mathrm{H}_{1 \mathrm{~b}}\right)$.

\section{METODOLOGIA}

A presente pesquisa busca analisar os efeitos da troca de pessoal sobre as práticas executadas pelas equipes de contabilidade. Para isso, a pesquisa utilizou análise quantitativa de informações com três modelos de regressão. Usualmente, os estudos institucionais adotam uma abordagem qualitativa para compreender os efeitos simbólicos das instituições, dado que instituições são um conjunto de práticas materiais e sistemas simbólicos (Suddaby \& Greenwood, 2009). Por outro lado, estudos quantitativos apresentam pontos fortes que podem ser utilizados na análise das estruturas formais que compõem um ambiente institucional (Suddaby \& Greenwood, 2009).

Os resultados foram apresentados em três etapas. Primeiro, foi realizada uma análise da relação entre a troca do Prefeito Municipal com a rotatividade das equipes de contabilidade nas Prefeituras Municipais. Na segunda etapa, apresenta-se uma análise sobre como as prefeituras estariam reorganizando suas equipes de contabilidade. Para essa análise, as prefeituras foram separadas em dois grupos, acima e abaixo da média nacional da formação dos servidores no ano de 2012. O objetivo foi analisar o comportamento das prefeituras a partir de sua organização prévia, tomando-se como corte o ano inicial da série analisada. Na terceira etapa, discute-se os efeitos da rotatividade em práticas executadas pelas equipes de contabilidade nas prefeituras. 
A equipe de contabilidade: tamanho e trocas de pessoal

O campo organizacional da contabilidade pública no Brasil compreende 5.570 municípios, 26 Estados e Distrito Federal, além do Governo Federal. Todos os municípios e órgãos internos são regidos pelo mesmo conjunto de leis no que se refere às tarefas executadas pela equipe de contabilidade. A lei 4.320/1964 regulamenta a elaboração e execução do orçamento público; a Lei Complementar 101/2000 trata de regras de conduta dos órgãos e gestores sobre o controle fiscal, além de portarias da Secretaria do Tesouro Nacional (STN) e Tribunais de Contas que regulamentam regras que também afetam as equipes de contabilidade. Equipes de contabilidade são contratadas e alocadas as suas funções com base em legislações locais. O Conselho Federal de contabilidade também atua no campo, seja na coerção ou treinamento de contadores (Diniz et al., 2015). Dessa forma, os membros do campo, além das equipes de contadores municipais, são os atores da Secretaria do Tesouro Nacional, Tribunais de Contas, Prefeitos e o Conselho Federal de Contabilidade.

As informações das equipes de contabilidade foram obtidas a partir da base de dados da Relação Anual de Informações Sociais (RAIS), no período de 2012-2016. Foram selecionados apenas os funcionários cadastrados com o código 2522 - "contadores e afins”, relacionados ao código de natureza jurídica 1031 - "Órgão Público do Poder Executivo Municipal”. Em seguida, foi efetuada a agregação das informações (movimentação de pessoal e escolaridade) por tipo de órgão municipal (Prefeitura, Autarquias, Fundações). Apenas os dados das Prefeituras Municipais foram analisados.

O tamanho da equipe é o total de funcionários classificados como 'contadores e afins' no final do ano. Diferentemente de outras métricas para calcular a rotatividade relativa das equipes (ex. Lopez et al., 2005; Campos \& Malik, 2008), a troca de pessoal foi calculada em termos absolutos pela soma dos funcionários que deixaram a organização (contadores desligados), com os novos funcionários que foram admitidos (contadores admitidos) - da mesma forma como os dados de movimentação de pessoal são apresentados no site do Cadastro Geral de Empregados e Desempregados (http://bi.mte.gov.br). Não foi analisado o motivo do desligamento, mas apenas sua movimentação. Na Tabela 1 a rotatividade é apresentada como uma proporção do tamanho da equipe de contadores daquela prefeitura. Por fim, a formação superior da equipe é a proporção dos funcionários com bacharelado em relação ao total de funcionários da equipe de contabilidade.

As informações descritivas estão apresentadas na Tabela 1. A pesquisa não excluiu outliers, como o total de 663 funcionários apresentados na tabela para um dos casos. Isso está de acordo com a proposta de Hair et al., (2005) em que a remoção de observações atípicas do modelo só deve acontecer se existirem provas de que essas estão verdadeiramente fora do normal e que não representam a origem da informação.

Tabela 1. Equipes de Contabilidade em Prefeituras

\begin{tabular}{|c|c|c|c|c|c|c|c|}
\hline Variáveis & Descrição & Fonte & $\mathbf{N}$ & Média & Min & Máx & DP \\
\hline Rotatividade (\%) & $\begin{array}{l}\text { Total da rotatividade em relação ao } \\
\text { tamanho inicial das equipes }\end{array}$ & RAIS & 16.692 & 0,329 & 0 & 34 & 0,982 \\
\hline Tamanho da equipe (n) & $\begin{array}{l}\text { Total de funcionários nas Prefeituras } \\
\text { registrados como 'contadores e } \\
\text { afins' }\end{array}$ & RAIS & 17.884 & 4,01 & 0 & 663 & 14,89 \\
\hline Formação superior (\%) & $\begin{array}{l}\text { Funcionários com formação mínima } \\
\text { de bacharelado (graduação), em } \\
\text { relação ao tamanho da equipe }\end{array}$ & RAIS & 17.884 & 0,62 & 0 & 1 & 0,396 \\
\hline
\end{tabular}

Fonte: Elaborada pelos autores, com dados da RAIS.

Nota. As descritivas apresentadas referem-se ao período de 2012 a 2016, para todos os municípios do país.

As prefeituras possuíam ao final de cada ano em média 4 contadores em suas equipes no período de 2013 a 2016. Para o ano de 2016, o total de 261 prefeituras não possuíam nenhum contador registrado. A rotatividade apurada no período foi em torno de $32,9 \%$ das equipes. As equipes eram compostas por $65 \%$ de pessoal com formação em nível superior no ano de 2016.

\section{Práticas executadas pelas equipes de contabilidade}

Foram estimados 3 modelos econométricos para a análise quantitativa dos dados. Cada modelo analisou uma prática executada pelas equipes de contabilidade, que não estão plenamente institucionalizadas no campo organizacional. Foram utilizadas como variáveis dependentes: (1) sucesso na aprovação de operações de crédito; (2) adequação às novas rotinas contábeis, e (3) acerto na utilização do PCASP. 
A primeira prática analisada (modelo 1) refere-se ao pedido de aprovação das operações de crédito enviado pelas prefeituras ao Ministério da Fazenda (LRF, art. 32). A prática não está institucionalizada, porque a estrutura formal para sua execução é variável no campo organizacional; as prefeituras utilizam-se de diferentes métodos e fontes de dados para apurar as informações necessárias, como discutido pela Confederação Nacional dos Municípios (CNM, 2018).

O procedimento é complexo, visto que uma série de informações deve ser disponibilizada, segundo roteiro previsto pelo Ministério da Fazenda, demandando alta especialização (Câmara dos Deputados, 2008). Pela característica das informações e regras necessárias para a obtenção de sua aprovação (demonstrativos contábeis, pleno reconhecimento contábil dos passivos, atendimento de limites, certidão do Tribunal de Contas, entre outros), comumente essa é uma atividade tipicamente atribuída à equipe de contabilidade. A variável capta a taxa de sucesso na aprovação de tais pedidos (pedidos bem-sucedidos $\div$ pedidos propostos). Foram considerados pedidos sem sucesso apenas aqueles cuja negativa não foi decorrente de limites legais, como endividamento e pessoal, de forma a restringir a análise a efeitos que dependam apenas do levantamento de informações contábeis.

A segunda prática analisa a adequação às novas rotinas contábeis (modelo 2), trazidas pela reforma da contabilidade patrimonial. Considerando que essa prática analisada está associada a transações que medem a adoção de uma contabilidade em regime por competência, cujo prazo de adoção dado pela STN (Portaria 548/2015) vai até 2024 , considera-se que estas práticas ainda não estão institucionalizadas no campo organizacional - mas sim no momento da difusão. Resultados de pesquisas recentes tem demonstrado a falta de institucionalização da contabilidade por competência (Ravanello, Marcuzzo \& Frey, 2015; Azevedo et al., 2017). Ainda, as mudanças são complexas, sobretudo ao considerar que os requisitos por uma contabilidade patrimonial se chocam com a lógica padrão dos contadores, que é orçamentária (Aquino \& Batley, 2016; Becker, Jagalla, \& Skærbæk, 2014).

A variável foi inspirada no Índice de Observância às Práticas de Convergência (IOPC) utilizado em pesquisas sobre adoção das IFRS (International Financial Reporting Standards) (Zonatto, 2011). Essa metodologia efetua um somatório das políticas contábeis adotadas. Considerou-se na análise apenas práticas associadas à decisão do contador e com baixa influência de softwares, conforme discutido em Azevedo et al. (2017). A variável apresenta uma variação entre 0 (nenhuma adotada) e 4 (adoção total). A Tabela 2 mostra as práticas consideradas para essa variável.

Tabela 2. Políticas contábeis utilizadas na variável (IOPC)

\begin{tabular}{|c|c|c|c|}
\hline \multirow{2}{*}{ Política } & \multirow{2}{*}{ Contas do SICONFI analisadas } & \multicolumn{2}{|c|}{ Adoção (\%) } \\
\hline & & 2014 & 2016 \\
\hline (i) Efetua ajuste para perdas de créditos & 1.1.2.9.1; 1.2.1.1.1.99 e 1.2.1.1.2.99 & 28,7 & 28,9 \\
\hline (ii) Reconhece ativos intangíveis & 1.2.4.0.0 & 5,1 & 5,4 \\
\hline (iii) Reconhece provisões & 2.1.7.0.0 e 2.2.7.0.0 & 29,4 & 29,6 \\
\hline $\begin{array}{l}\text { (iv) Separa o resultado do exercício e exercícios } \\
\text { anteriores no patrimônio Líquido (PL) }\end{array}$ & 2.3.7.1.1.01 e 2.3.7.1.1.02 & 56,9 & 65,2 \\
\hline
\end{tabular}

Fonte: Elaborada com base nos dados do Sistema de Informações Contábeis e Fiscais do Setor Público Brasileiro (SICONFI).

A terceira prática (modelo 3) analisa o percentual de adequação na adoção do novo plano de contas nacional (PCASP) pelas prefeituras. A adequação é observada nas contas que operacionalizam a confrontação das contas contábeis do ativo e passivo, criadas para fins de consolidação (STN, 2018). Por essa regra, exige-se que na organização das informações contábeis sejam identificados separadamente os ativos e passivos entre órgãos dentro do mesmo município. Por exemplo, um direito que uma autarquia tenha a receber da Prefeitura Municipal seria considerado como um ativo intra para a autarquia e um passivo intra para a Prefeitura.

Essa segregação de contas recebe o nome de ativos e passivos intragovernamentais. Considera-se que a prática não esteja institucionalizada, visto que os conceitos introduzidos pelo plano de contas nacional (PCASP) a partir de 2013 ainda estão sendo assimilados pelos atores do campo organizacional (Jacob \& Santos, 2015). Considera-se que esse novo mecanismo contábil possui baixa complexidade, pois essa nova metodologia requer apenas uma adequação das contas contábeis em níveis diferentes dos anteriormente adotados. Em suma, o que muda é apenas o registro da conta para o reconhecimento. A variável foi calculada através da fórmula a seguir, cuja lógica é observar o acerto de forma residual.

$$
\text { AcertoPCASP }=\text { módulo }\left(\text { Ativo }_{\text {intra }}+\text { Passivo }_{\text {intra }}\right)-\text { módulo }\left(\text { Ativo }_{\text {intra }}-\text { Passivo }_{\text {intra }}\right)
$$




\section{Variáveis e modelos estimados}

Foram estimados três modelos econométricos, nos quais cada prática executada pelas equipes de contabilidade foi utilizada como uma variável dependente. As práticas selecionadas variam quanto à complexidade de execução, dentre aquelas práticas não institucionalizadas no campo organizacional da contabilidade pública, independentemente do tempo de adoção (Tabela 3).

Tabela 3. Características das práticas analisadas e sua relação com as hipóteses - variáveis dependentes

\begin{tabular}{lcccc}
\hline \multicolumn{1}{c}{ Práticas analisadas } & $\begin{array}{c}\text { Período } \\
\text { analisado }\end{array}$ & Complexidade & Hipótese & $\begin{array}{c}\text { Efeito } \\
\text { Esperado }\end{array}$ \\
\hline (1) Sucesso na aprovação de operações de crédito & 2012 a 2016 & Alta & $\mathrm{H}_{1 \mathrm{a}}$ & $(-)$ \\
(2) Adequação às novas rotinas contábeis & 2014 a 2016 & Alta & $\mathrm{H}_{1 \mathrm{a}}$ & $(-)$ \\
(3) Acerto na utilização do PCASP & 2014 a 2016 & Baixa & $\mathrm{H}_{1 \mathrm{~b}}$ & $(+)$ \\
\hline
\end{tabular}

Fonte: Elaborada pelos autores.

Os modelos 1 e 3 foram estimados por meio de uma regressão em painel com efeitos aleatórios, e o modelo 2 utilizou um modelo Probit ordenado. O uso desse modelo se justifica, pois nesse caso os valores na variável dependente possuem um ordenamento na adoção das práticas. Foram realizados testes para verificar a adequação dos modelos, e a Tabela 4 apresenta as variáveis independentes e de controle utilizadas.

Tabela 4. Variáveis independentes e de controle dos modelos estimados

\begin{tabular}{|c|c|c|c|}
\hline Variáveis independentes & & Descrição & Fonte \\
\hline Rotatividade & \multicolumn{2}{|c|}{ Soma das entradas e desligamentos de pessoal da equipe de contabilidade. } & (2) \\
\hline Tamanho da equipe & \multicolumn{2}{|c|}{ Funcionários nas equipes de contabilidade em Prefeituras (n) no final do ano } & (2) \\
\hline $\begin{array}{l}\text { Equipe de contabilidade com } \\
\text { formação superior }\end{array}$ & \multicolumn{2}{|c|}{ Equipe com formação mínima de bacharelado em relação ao total (\%) } & (2) \\
\hline Variáveis de controle & Forma de mensuração & Justificativa & Fonte \\
\hline Prefeito reeleito em $2013^{(i)}$ & $\begin{array}{l}\text { Dummy para (1) prefeito } \\
\text { reeleito; }(0) \text { não reeleito }\end{array}$ & $\begin{array}{l}\text { Controlar o efeito da reeleição de prefeitos sobre } \\
\text { a rotatividade das equipes de contabilidade. } \\
\text { Justifica-se pelos ajustes da gestão e acordos } \\
\text { feitos na campanha. }\end{array}$ & (3) \\
\hline Ano de eleição $0^{(i)}$ & $\begin{array}{l}\text { Dummy para (1) ano de } \\
\text { 2013; (0) demais }\end{array}$ & $\begin{array}{l}\text { Controlar efeitos do } 1^{\circ} \text { ano de governo, conforme } \\
\text { Lopes (2015) }\end{array}$ & (4) \\
\hline O município é capital & $\begin{array}{l}\text { Dummy para (1) capitais; } \\
\text { (0) demais }\end{array}$ & $\begin{array}{l}\text { Efeitos decorrentes da diferença na estrutura } \\
\text { e pressões a que estão sujeitas as capitais dos } \\
\text { estados para os demais municípios, conforme } \\
\text { Azevedo e Cabello (2018) }\end{array}$ & (4) \\
\hline Despesa liquidada total $(\log )$ & $\begin{array}{l}\text { Medida de complexidade } \\
\text { contábil }\end{array}$ & $\begin{array}{l}\text { Proxy para captar complexidade contábil. } \\
\text { Assume-se que quanto maior a movimentação } \\
\text { orçamentária, maior seria a complexidade } \\
\text { contábil, pelo seu volume de transações, } \\
\text { que aumentaria os ativos e passivos a serem } \\
\text { controlados. }\end{array}$ & (1) \\
\hline $\begin{array}{l}\text { O município possui Controle } \\
\text { Interno }\end{array}$ & $\begin{array}{l}\text { Dummy }(1) \text { possui gastos } \\
\text { com controle interno }(0) \\
\text { não possui. }\end{array}$ & $\begin{array}{l}\text { Controlar os efeitos que a existência de sistema } \\
\text { de controle interno teria sobre a contabilidade, } \\
\text { conforme Aquino e Azevedo (2015) }\end{array}$ & (1) \\
\hline Tribunais de Contas & $\begin{array}{l}\text { Todos os municípios } \\
\text { receberam (1) } \\
\text { identificando o TC ao qual } \\
\text { é jurisdicionado, e }(0) \text { para } \\
\text { os demais. }\end{array}$ & $\begin{array}{l}\text { Série de variáveis dummies para controlar os } \\
\text { efeitos das particularidades dos Tribunais de } \\
\text { Contas, conforme Lino e Aquino (2018). }\end{array}$ & (4) \\
\hline
\end{tabular}

Fonte: Elaborada pelos autores.

Notas: (i) Variáveis presentes apenas no modelo 1. (ii) Todas as variáveis foram levantadas por município. (iii) Fontes: (1) SICONFI - Sistema de Informações Contábeis e Fiscais do Setor Público Brasileiro; (2) RAIS - Relação Anual de Informações Sociais; (3) SIOPS - Sistema de Informações sobre Orçamentos Públicos em Saúde; (4) Construída pelos autores. 


\section{Resultados e discussão}

A seção demonstra a troca das equipes técnicas de contabilidade em prefeituras, associada com a troca de governantes; apresenta e discute a composição destas equipes (formação e tamanho), associada com a troca de pessoal, e finaliza com a apresentação dos impactos das trocas de pessoal na execução e adoção de práticas de contabilidade.

\section{A troca de governo e a troca das equipes de contabilidade nas Prefeituras Municipais}

A troca de pessoal no setor público não se restringe aos cargos de direção e assessoramento, como em geral o tema é tratado (López et.al, 2015). Entre 2012 e 2016, as prefeituras analisadas apresentaram uma média de 33\% de rotatividade dos membros das equipes de contabilidade. Ao considerar o contexto do setor público brasileiro, que exige o concurso público como forma básica de ingresso aos cargos da burocracia, possibilitando o alcance de estabilidade, a taxa de rotatividade é alta. Comparativamente, a rotatividade em cargos de livre nomeação federal entre 1999 e 2013 foi de 30\% (Lopez et al., 2015). Dada a diferença na estabilidade desses cargos (livre nomeação sem estabilidade versus cargo técnico estável), o resultado reforça a relevância da presente discussão.

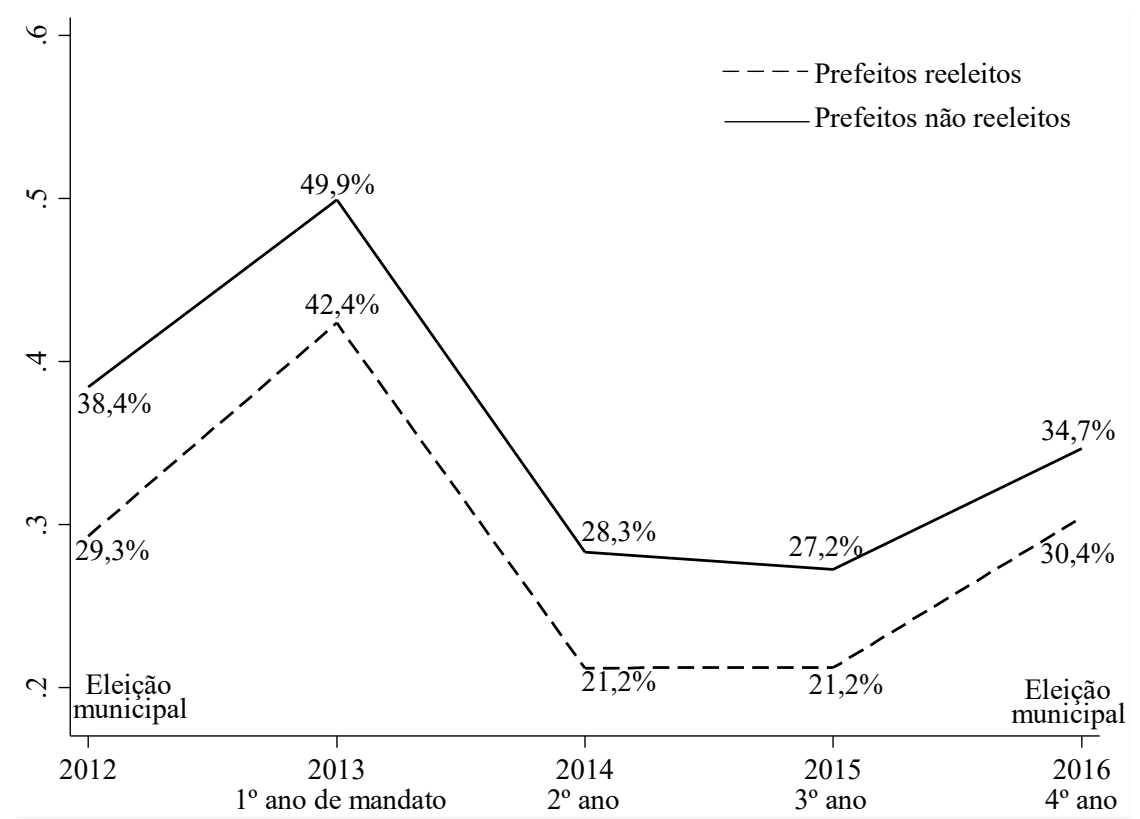

Figura 1. Rotatividade na equipe de contabilidade em Prefeituras Municipais, prefeitos reeleitos / não reeleitos (2013)

Fonte: Elaborada pelos autores.

Notas: (1) Média de rotatividade entre 2013 e 2016: com troca de prefeitos: (49,9\%); com reeleição de prefeito: $(29,6 \%)$. (2) Rotatividade: (admissões + desligamentos) $\div$ tamanho da equipe.

A Figura 1 demonstra que existe um padrão de rotatividade nas prefeituras no $1^{\circ}$ ano do mandato, independente da troca do prefeito. Porém, a rotatividade das equipes foi menor para as Prefeituras em que houve a reeleição do prefeito. Assim, a troca do chefe do executivo parece potencializar as trocas de pessoal(diferença de média significante, p-value 0,000). Entre 2013 e 2016, as prefeituras com troca de prefeitos tiveram uma rotatividade das equipes de contabilidade de 49,9\%, frente a uma rotatividade de $29,6 \%$ para aquelas cujos prefeitos mantiveram-se no poder. O padrão de rotatividade na equipe de contabilidade dos municípios segue o mesmo padrão da movimentação dos cargos DAS federal, cuja frequência é maior no primeiro ano do mandato e cai nos anos subsequentes (Lopez et.al, 2015). Porém, observou-se que nos municípios a rotatividade também aumentou no último ano do mandato.

Sugere-se que os efeitos de patronagem característicos do presidencialismo de coalizão, com distribuição de cargos como instrumento para garantir a governabilidade, podem ir além dos resultados em geral discutidos que tratam apenas a rotatividade sobre os cargos de direção e assessoramento (Lopez et al., 2015). No caso das prefeituras, o efeito também foi percebido sobre os cargos técnicos, que deveriam ser concursados e estão sendo contratados de outra forma, via "contratação por excepcional interesse público" ou "comissionados". 
Em Pernambuco no ano de 2016 os cargos efetivos correspondiam a $66 \%$ e os não efetivos a $34 \%$ das equipes de contabilidade. Ressalta-se que a proporção de cargos efetivos diminuiu, pois em 2012 estes correspondiam a 74\%, o que pode indicar que a baixa atenção dos órgãos de controle externo sobre essa questão tem criado incentivos para que a situação se agrave. A despeito disso, diversos entendimentos dos Tribunais de Contas têm reiterado essa exigência legal de concurso para contadores (ex. TCE-PR, pré-julgado 6/2008; TCEMT, Resolução de Consulta n 31/2010).

\section{A reforma da contabilidade e a reorganização das equipes de contabilidade}

A alta troca em cargos de contabilidade poderia ser uma resposta dos municípios frente às mudanças na contabilidade pública já que os diversos órgãos podem buscar a reestruturação de seus quadros, visto que (i) as novas práticas executadas pelas equipes de contabilidade requerem habilidades que vão além daquelas dos profissionais com nível técnico (Carneiro \& Neto, 2015), (ii) existe crescente demanda por prestações de contas aos Tribunais de Contas (Lino \& Aquino, 2018) e à Secretaria do Tesouro Nacional. Contudo, alerta-se que tal estruturação pode não decorrer necessariamente dos contadores, secretários ou prefeitos nos municípios entenderem as mudanças como sendo importantes, mas apenas por considerarem as incertezas e a possibilidade de eventuais punições, como a retenção de recursos de transferências de outras esferas de governo pelo não atendimento às regras (Sasso, 2017).

Entre 2012 e 2016, a proporção de profissionais de contabilidade com nível superior nas equipes de contabilidade em prefeituras municipais aumentou de $58,6 \%$ para $65,1 \%$. Essa mudança acompanha a proporção de profissionais formados em ciências contábeis de 64,97\% em 2016, segundo dados do CFC.

Foram observados dois padrões de respostas. Primeiro, prefeituras cujas equipes já em 2012, tinham uma proporção de nível superior menor que média nacional (de 58,6\% da equipe) e diminuíram ainda mais (diminuição de $14 \%$ com nível superior e crescimento de 18\% com nível técnico). Segundo, prefeituras que já estavam acima da média nacional, aumentaram ainda mais o nível superior nas equipes (crescimento de 35\% com ensino superior e diminuição de $49 \%$ com ensino técnico). Para cada um dos grupos observados (prefeituras abaixo e acima da média nacional em 2012) a Figura 2 discrimina a variação do percentual de profissionais de contabilidade com ensino superior nas equipes das prefeituras, comparando por Estado da federação. Foi encontrada diferença de média na formação dos profissionais ( $p$-value 0,000$)$ entre os grupos que se encontravam acima ou abaixo da média nacional de formação de equipes em 2012. A diferença foi mantida para todo o período analisado.
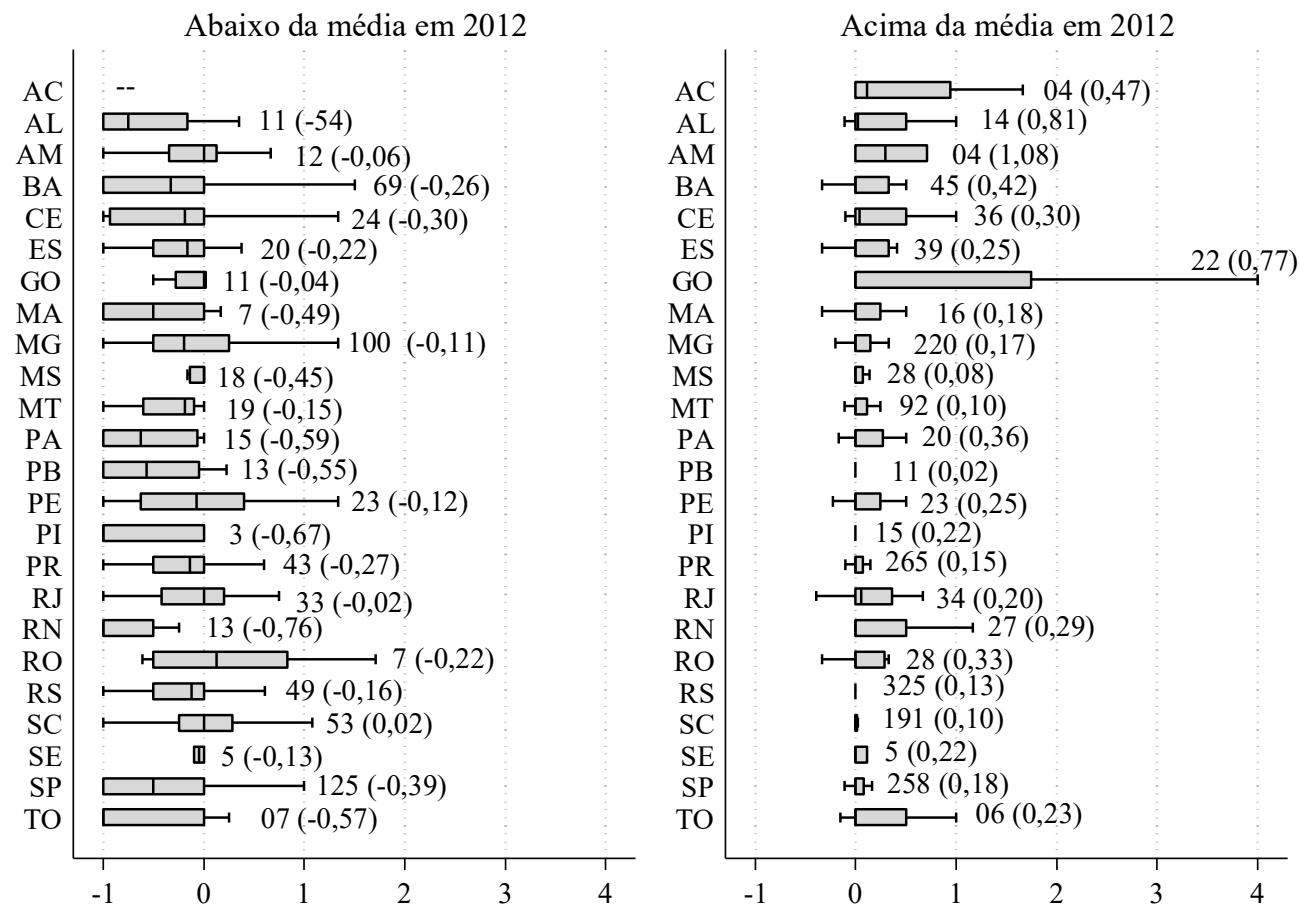

Figura 2. Proporção de contabilistas com ensino superior nas equipes, variação entre 2012 e 2016 Fonte: Elaborada pelos autores.

Notas: (1) Os números apresentam a quantidade de municípios, e entre parênteses a variação do percentual da equipe de contabilidade com grau superior em 2016 em relação ao ano de 2012. (2) Os grupos foram apresentados separando os que estavam acima e abaixo da média de contadores com ensino superior em 2012. (3) A escala horizontal de -1 a 4, significa a variação percentual máxima e mínima observada nos casos analisados. Ex. Um município que tinha 1 contador em 2012 e passou a ter 4 contadores em 2016 aumentou em 3 vezes sua equipe. 
Ressalta-se que desde o ano 2015 profissionais de nível técnico não podem mais se registrar para exercer a profissão (Lei 12.249/2010), mantidos os direitos dos técnicos já registrados. Dessa forma, concursos públicos ainda têm oferecido cargos para profissionais de nível técnico: entre 2016 e 2018 foram mais de 200 concursos públicos para nível técnico em órgãos espalhados por vinte e quatro estados. Uma explicação desta dinâmica pode ser o menor salário oferecido. De qualquer forma, os processos de seleção para ingresso na carreira, em geral, ainda se baseiam no conhecimento técnico (Júnior et al., 2008), o que pode ser um entrave para a reforma.

Outro fator que pode indicar a busca pela reorganização das equipes de contabilidade nas prefeituras é o tamanho das equipes. Entre 2011 e 2016 as equipes aumentaram em tamanho em média 19,6\%, atingindo o número de 3,7 contadores em 2016 (Figura 3). Analisando o tamanho da equipe, mantendo a mesma unidade de análise pela formação das equipes (nível superior e técnico), observa-se comportamento similar (aumento de 18\% para os abaixo da média e $21 \%$ para os acima).
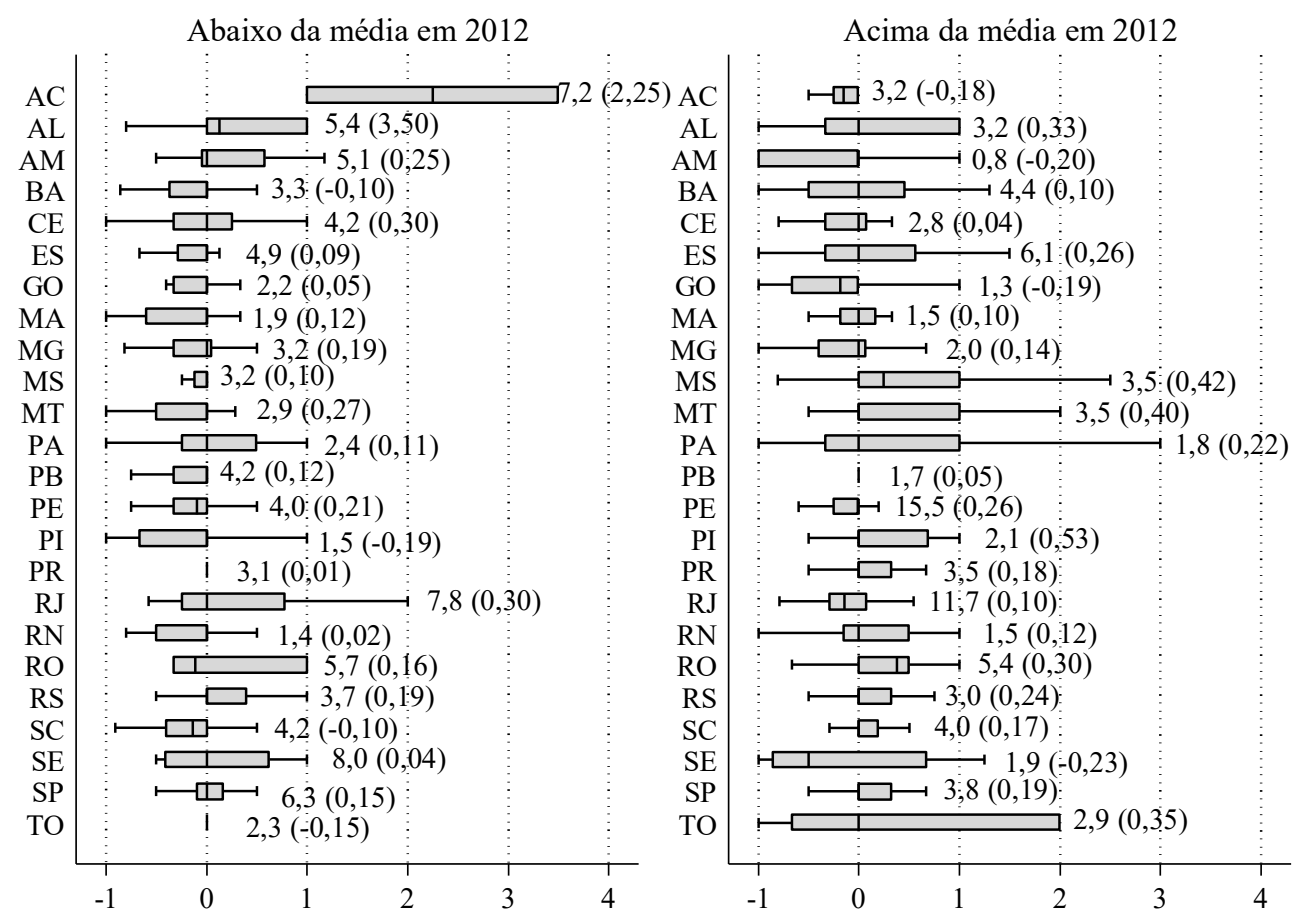

Figura 3. Tamanho da equipe de contabilidade, variação entre 2012 e 2016

Fonte: Elaborada pelos autores.

Notas: (1) Os números apresentam o tamanho médio da equipe no ano de 2016, e entre parênteses a média da variação do tamanho da equipe entre 2012 e 2016. (2) Os grupos foram apresentados separando os que estavam acima e abaixo da média de contadores com ensino superior em 2012. (3) A escala horizontal de -1 a 4, significa a variação percentual máxima e mínima observada nos casos analisados. Ex. Um município que tinha 1 contador em 2012 e passou a ter 4 contadores em 2016 aumentou em 3 vezes sua equipe.

No caso do tamanho médio das equipes de contabilidade em prefeituras, no ano de 2016, foi encontrada a diferença de média ( $\mathrm{p}$-value 0,000 ) entre os grupos que se encontravam acima ou abaixo da média nacional de formação de equipes em 2012. No caso dos tamanhos da equipe, houve maior crescimento da equipe daqueles que estão acima da média. Este mesmo grupo possui equipes menores do que municípios com equipes menos qualificadas (p-value 0,000), indicando que seria necessária uma menor quantidade de servidores para realizar as atividades contábeis, quando possuem maior qualificação.

A análise conjunta leva a discussão de que, no longo prazo, ocorreria um aumento na defasagem técnica de algumas prefeituras em relação a outras. Neste cenário, um movimento de reforma da contabilidade tenderia a ser conduzido com maior grau de sucesso em algumas prefeituras, enquanto outras se tornariam retardatárias na adoção das práticas. O mesmo aconteceria em qualquer movimento de adoção de prática a ser executada pela equipe de contabilidade que necessite de um contingente significativo e/ou de profissionais capacitados. Contudo, além da capacidade técnica em termos de qualificação e número de profissionais, é necessário se avaliar a continua troca destes servidores. Tal rotatividade possibilitaria a institucionalização incompleta de práticas e também afetaria a implementação de reformas - como será visto na próxima seção. 


\section{Efeitos das trocas de pessoal em práticas executadas pelas equipes de contabilidade}

A rotatividade das equipes causa diferentes efeitos sobre as práticas executadas pelas equipes de contabilidade, que estão associados com as suas características (Tabela 5). A rotatividade apresentou efeito negativo sobre as práticas não institucionalizadas com alta complexidade (modelos 1 e 2) e efeito positivo na prática com baixa complexidade (modelo 3), confirmando as hipóteses propostas neste trabalho. $\mathrm{O}$ tamanho da equipe de contabilidade e a qualificação dos servidores foram variáveis significantes para as práticas de alta complexidade, atuando no sentido inverso da rotatividade, e não estão associadas com tarefas de baixa complexidade. A manutenção do prefeito também foi significante, no modelo (1) em que se aplicava, e impacta positivamente a execução de tarefas complexas.

Como já discutido, tarefas complexas demandariam capital de recursos e capital institucional para sua adoção (Oliver, 1997). No caso da operação de crédito (modelo 1), a rotatividade diminuiu a sua taxa de aprovação. Isso aconteceria, pois, conforme discutido na sessão de metodologia, existe alta complexidade na organização dos documentos e informações necessários para o acompanhamento e cumprimento de prazos. Dessa forma, quando a equipe é trocada, recursos são perdidos, e é necessário o aprendizado dessas regras. Apesar do tamanho da equipe e formação qualificada aumentarem a probabilidade de aprovação de operações de crédito, a entrada de novos funcionários, mesmo que possuam formação superior, seria suplantada pela falta de capital institucional. Como visto em estudo de Azevedo (2016), novos profissionais com formação em nível superior não garantem a mudança em práticas executadas pela equipe de contabilidade.

Tabela 5. Resultados - influência da rotatividade, tamanho e formação das equipes nas práticas

\begin{tabular}{|c|c|c|c|c|c|c|}
\hline & \multirow{2}{*}{\multicolumn{2}{|c|}{$\begin{array}{c}\text { Modelo } 1 \\
\text { Aprovação Operação de } \\
\text { Crédito }(\%)\end{array}$}} & \multirow{2}{*}{\multicolumn{2}{|c|}{$\begin{array}{c}\text { Modelo } 2 \\
\text { Adequação às novas } \\
\text { rotinas contábeis }\end{array}$}} & \multirow{2}{*}{\multicolumn{2}{|c|}{$\begin{array}{c}\text { Modelo } 3 \\
\text { Acerto plano de contas }\end{array}$}} \\
\hline & & & & & & \\
\hline & Coeficiente & $\mathrm{P}>|\mathrm{z}|$ & Coeficiente & $\mathrm{P}>|\mathrm{z}|$ & Coeficiente & $\mathrm{P}>|\mathrm{z}|$ \\
\hline Rotatividade da equipe (log) (a) & $-0,0528$ & $0,0100 * *$ & $-0,0722$ & $0,0140 * *$ & 0,1744 & $0,0730^{*}$ \\
\hline Tamanho da equipe (log) (b) & 0,0608 & $0,0030^{* * *}$ & 0,0954 & $0,0010 * * *$ & $-0,0007$ & 0,9950 \\
\hline Formação superior (em \%) & 0,1597 & $0,0050^{* * *}$ & 0,2642 & $0,0000 * * *$ & $-0,2864$ & 0,2920 \\
\hline Reeleição do prefeito (2013) & 0,1986 & $0,0000^{* * *}$ & -- & -- & -- & -- \\
\hline Ano eleitoral & 0,0326 & 0,4360 & 0,3467 & $0,0000 * * *$ & 0,3726 & $0,0060 * * *$ \\
\hline Município é capital de estado & 0,0828 & 0,4840 & $-0,4893$ & $0,0220 * *$ & $-0,0772$ & 0,9180 \\
\hline Despesa liquidada total (log) & $-0,0566$ & $0,0000 * * *$ & 0,3961 & $0,0000 * * *$ & 11,658 & $0,0000 * * *$ \\
\hline Possui Controle Interno & 0,0416 & 0,2000 & 0,0947 & $0,0330 * * *$ & 0,1296 & 0,4310 \\
\hline Tribunal de Contas (dummies) & -- & $\mathrm{Na}$ & & & & \\
\hline Intercepto & 1,3390 & $0,0000^{* * *}$ & -- & -- & $-6,1190$ & $0,0000 * * *$ \\
\hline $\mathrm{N}$ & & 789 & & 2.851 & & 1.664 \\
\hline R2 apurado \pm & & 0,0718 & & 0,1804 & & 0,2594 \\
\hline $\mathrm{Chi}^{2} / \mathrm{F} \dagger$ & & 0,0000 & & 0,0000 & & 0,0000 \\
\hline
\end{tabular}

Fonte: Elaborada pelos autores.

Notas: (a) Rotatividade da equipe: soma de admitidos e desligados no período, em log. (b). Tamanho da equipe ao final do exercício, em log. (na) não foram apresentados os resultados da variável de controle TC. (--) não faz parte do modelo. (1) Todos os modelos consideraram o período de 2013 a 2016. (2) Para os modelos 1 e 3 foram realizados testes para decidir a melhor adequação dos modelos: Hausman, BreuschPagan; Chow. (3) Testes adicionais utilizando a rotatividade em razão do tamanho da equipe (medida relativa) também foram efetuados. Os resultados de significância e direção do impacto (sinal) não foram alterados para os modelos 1 e 2, e houve perda de significância no modelo 3 - sendo utilizadas variáveis de controle específicas. Consideramos que a essência da discussão não se alteraria nos outros testes, pois a rotatividade permanece afetando negativamente as práticas complexas, o que reforça a hipótese discutida. \pm Pseudo- $\mathrm{R}^{2}$ para o modelo Probit ordenado e R2 overall para os modelos GLS. $\uparrow$ Chi²-test para o modelo Probit ordenado e F-test para os modelos GLS. $*$ p $<0,1 * * \mathrm{p}<0,05$ $* * * \mathrm{p}<0,01$

Nas seções anteriores as análises mostraram que a reeleição do prefeito sinaliza menor rotatividade das equipes. O modelo em análise apresenta que a reeleição do prefeito e a continuidade da gestão resultam em maior taxa de sucesso na aprovação das operações de crédito. Essa análise sugere que os impactos da troca de governantes sobre a equipe técnica podem afetar as práticas executadas pela burocracia - testes em pesquisas futuras podem evidenciar esta hipótese. 
A presença de rotatividade afeta negativamente a adoção e execução de novas rotinas contábeis (modelo 2). Dada a sua complexidade e dependência de outros setores, o efeito pode decorrer da necessidade das equipes de contabilidade possuírem relações com outros servidores e setores e habilidade de convencimento ou poder para incentivá-los a desenvolver essas novas práticas. Tal dinâmica está associada ao conceito de capital institucional, trazido por Oliver (1997). No contexto da lógica orçamentária vigente no setor público e da falta de capital institucional de determinados atores, como os novos servidores, mudanças organizacionais são dificultadas (como visto em Lino et al., 2019). O tamanho da equipe influencia positivamente estas práticas, o que estaria associado à quantidade de novas informações que deveriam ser necessariamente registradas e controladas. No mesmo sentido, o conhecimento prévio da equipe sobre tais práticas é necessário para sua adoção e execução, o que explica sua relação positiva com profissionais com formação qualificada e adoção das práticas.

Já para as práticas com menor complexidade, como é o caso do acerto do plano de contas (modelo 3), a rotatividade aumenta a possibilidade de adoção e execução. Segundo a teoria, isso ocorreria, pois os contadores mais antigos na função podem não estar tão atentos ou resistirem ativamente às novas práticas que surgiram (Oliver, 1991). Por outro lado, os novos servidores podem estar mais atentos e possuírem maior preocupação com responsabilização (Greenwood \& Hinnings, 1996). Estudos posteriores poderiam avaliar em detalhes esse efeito. Como as práticas apresentam menor complexidade e dependência de terceiros, o único bloqueio para sua execução seria a falta de recursos (neste caso, conhecimento mínimo sobre a execução da prática, aquém do ofertado em nível superior). Criação de capital institucional não se faz necessária, de forma que servidores públicos mais atentos impactam positivamente sua execução. Além disso, explica-se porque o tamanho da equipe não afeta o desempenho da tarefa.

Analisando os resultados em conjunto, o contexto da alta rotatividade observada nas equipes de contabilidade e os reflexos nas práticas executadas por essas equipes sugerem que o processo de institucionalização de novas práticas, como as propostas pela reforma contábil, pode ser prejudicado. Se a cada 4 anos existe a possibilidade de troca do prefeito, e a consequente troca de parte das equipes de contabilidade, é de se esperar que a institucionalização de novas práticas complexas seja menos provável. Apenas as práticas mais simples acabariam sendo adotadas, ou aquelas cuja coerção seja mais direta.

\section{CONCLUSÕES E IMPLICAÇÕES}

O artigo analisou o impacto das trocas de pessoal em equipes de contabilidade na execução e adoção de práticas executadas pelas equipes de contabilidade em Prefeituras brasileiras. Os resultados indicam que existe a rotatividade de servidores de contabilidade nestes órgãos e que ela impacta de forma diferente a execução de práticas pela equipe de contabilidade - dependendo do grau de complexidade desta execução.

Assim como em Meier \& Hicklin (2008), apontamos que tal rotatividade de pessoal não é algo necessariamente ruim. No caso das práticas executadas por equipes de contabilidade no Brasil, práticas simples são positivamente relacionadas às trocas de pessoal; práticas complexas por sua vez são negativamente impactadas pela rotatividade.

Os resultados trazem implicações para a organização dos municípios, os órgãos normatizadores e para o controle externo. Contudo, dado o ambiente regulatório brasileiro, com exigência constitucional sobre concurso como regra para ingresso no serviço público, e especificamente no caso das equipes de contabilidade sobre a extinção de cargos técnicos (Lei Federal 12.249/2010), algumas mudanças deveriam ser levadas em conta para promover os efeitos positivos e mitigar os efeitos negativos da rotatividade.

Quanto à organização dos municípios, sugere-se três possibilidades para a execução das tarefas mais simples. Primeiro, poderiam ser executadas por técnicos em contabilidade, não necessariamente estáveis, que estariam sujeitos a uma maior rotatividade, e não necessitariam possuir uma estrutura de carreira no setor público. Segundo, buscar cada vez mais sua execução via automatização com softwares, diminuindo dependência de pessoal para sua execução. Por fim, a terceira possibilidade seria buscar sua execução via terceirização de mão-de-obra.

Por outro lado, em relação às tarefas mais complexas, os Prefeitos poderiam com ganhos de retenção de conhecimento e expertise estruturar uma carreira para os contadores, gerando os incentivos para que a rotatividade diminuísse nesses cargos - aumentando a possibilidade dessas tarefas serem executadas. Dessa maneira, a gestão da rotatividade passaria a ser uma escolha dos gestores públicos em busca da maior efetividade organizacional e eficiência na gestão. 
Quanto à normatização de diversas práticas executadas pela equipe de contabilidade, além das ações desenvolvidas pela Secretaria do Tesouro Nacional e Tribunais de Contas (principalmente no que se refere à reforma contábil), sugere-se que o Conselho Federal de Contabilidade também teria papel relevante devido a diversos fatores: pela (i) sua competência legal para a redefinição das atividades permitidas para a execução de técnicos de contabilidade em detrimento de atividades específicas para contadores graduados; (ii) sua capilaridade para capacitações decorrentes do Programa de Educação Continuada já em operação no país - porém, ainda pouco utilizado no setor público, e pela (iii) competência legal de punição direta aos contadores e técnicos pela não execução das práticas conforme previsto nas normas. Este conjunto de atividades geraria forte incentivo à adoção e manutenção de práticas executadas pelas equipes de contabilidade, e auxiliaria na geração de capital de recursos (conhecimento) mesmo no atual contexto de rotatividade das equipes.

Deve-se considerar também o público alvo e mensagem dessas capacitações. Aqui, Tribunais de Contas poderiam, além de apenas apresentar e discutir o conteúdo das práticas, atuar no convencimento dos atores com poder de decisão, como Secretários e Prefeitos - não se restringindo apenas aos contadores. Neste contexto, Tribunais de Contas poderiam difundir boas-práticas relacionadas à carreira de contador nas diversas prefeituras, além de averiguar o montante de servidores técnicos ou terceirizados. Essa atuação implicaria em aumento no capital institucional relacionado às práticas executadas pelas equipes de contabilidade em prefeituras, criando os incentivos para a gestão da rotatividade nas Prefeituras jurisdicionadas.

Finalmente, a análise empregada no presente artigo não permite discutir se a rotatividade das equipes de contabilidade estaria associada de alguma forma à oferta de cargos como barganha política como recurso para manter ou formar a coalizão. Contudo, é possível que em algumas situações o uso de cargos temporários chegue a níveis operacionais. Assim, pesquisas futuras na temática de presidencialismo de coalizão poderiam analisar o efeito da coalizão na rotatividade de equipes técnicas.

\section{REFERÊNCIAS}

Andrews, R., \& Boyne, G.A. (2014). Task complexity, organization size, and administrative intensity: The case of UK universities. Public Administration, 92(3),656-672. DOI: https://doi.org/10.1111/padm.12078

Aquino, A.C.B., \& Batley, R.A. (2016). Accounting and Fiscal Reforms in Brazil. In: EGPA Annual Conference. Utrech.

Aquino, A. C. B. de, \& Azevedo, R. R. de. (2015). O “ir”realismo orçamentário nos municípios brasileiros. Business and Management Review, 5(1), 210-224.

Azevedo, R. R. de. (2016). Resistências ao planejamento de resultados e a lógica orçamentária dominante em municípios. Tese de doutorado. Ribeirão Preto: Universidade de São Paulo.

Azevedo, R. R. de.; Aquino, A.C.B., Silva, C., \& Neves, F. (2017). Efeito da mudança de prazos de adoção e características das políticas contábeis na reforma da contabilidade patrimonial em municípios. In: $X$ Congresso de Administração, Sociedade e Inovação. Petrópolis/RJ.

Azevedo, R. R., \& Cabello, O. G. (2018). Controle e Transparência Sobre os Gastos Tributários em Municípios Brasileiros e Sua Relação Com as Transferências Intergovernamentais. In: Congresso USP de Contabilidade. São Paulo/SP: Universidade de São Paulo.

Becker, S.D., Jagalla, T., \& Skærbæk, P.(2014). The translation of accrual accounting and budgeting and the reconfiguration of public sector accountants' identities. Critical Perspectives on Accounting, 25(4-5),324338. DOI: https://doi.org/10.1016/j.cpa.2013.05.004

Bertholini, F., \& Pereira, C. (2017). Pagando o Preço de Governar: Custos de Governabilidade no Presidencialismo de Coalizão Brasileiro. Revista de Administração Pública, 51(4),528-550. DOI: http://dx.doi.org/10.1590/00347612154969

Câmara dos Deputados. (2008). Responsabilidade da Gestão Pública: os desafios dos municípios. Linhares, J. (relator). Brasília.

Campos, C.V. de A, \& Malik, A.M. (2008). Satisfação no trabalho e rotatividade dos médicos do Programa de Saúde da Família. Revista de Administração Pública, 42(2), 347-368. DOI: http://dx.doi.org/10.1590/S003476122008000200007

Carley, K.(1992). Organizational Learning and Personnel Turnover. Organization Science, 3(1),20-46. 
Carneiro, A.F., \& Neto, J.M.S. (2015). Competências essenciais dos profissionais contábeis em face da nova contabilidade pública sob a perspectiva dos contadores de Rondônia. Gestão, Finanças e Contabilidade, 5(3),100-122. DOI: http://dx.doi.org/10.18028/2238-5320/rgfc.v5n3p100-122

Cavalcante, P., Lotta, G.S., \& Oliveira, V. E. de. (2018). Do insulamento burocrático à governança democrática: as transformações institucionais e a burocracia no Brasil. In: Burocracia e políticas públicas no Brasil: interseções analíticas (p. 59-83). Brasília: Ipea.

CNM. (2018). Atenção: cadastro da Dívida Pública pode levar centenas de Municipios ao Cauc. Disponível em: $<$ https://www.cnm.org.br/comunicacao/noticias/atencao-cadastro-da-divida-publica-pode-levar-centenas-demunicipios-ao-cauc $>$. Acesso em nov/2018.

DiMaggio, P.J. (1988). Interest and agency in institutional theory. In: L.G.Zucker (Ed.), Institutional patterns and culture (p.3-22). Cambridge: Ballinger Publishing Company.

Diniz, J.A., Silva, S.F.S., Santos, L.C., \& Martins, V.G. (2015). Vantagens da Implantação das Ipsas na Contabilidade Pública Brasileira: Análise da percepção dos membros do GTCON. Revista de Educação e Pesquisa Em Contabilidade, 9(3),275-294. DOI: https://doi.org/10.17524/repec.v9i3.1226

Greenwood, R., \& Hinings, C.R. (1996). Understanding radical organizational change: Bringing together the old and the new institutionalism. Academy of Management Review, 21(4), 1022-1054. DOI: https://www.jstor. org/stable/259163

Hair, J.F., Black, W.C., Babin, B.J., Anderson, R.E., \& Tatham, R.L. (2009). Análise multivariada de dados. Porto Alegre: Bookman Editora.

Haunschild, P., \& Chandler, D. (2008). Institutional-Level Learning: Learning as a Source of Institutional Change. In R. Greenwood, C. Oliver, K. Sahlin, \& R. Suddaby (Eds.), Handbook of Organizational Institutionalism (Vol.1, p.624-649). London: Sage.

Jacob, A.M., \& Santos, M.E. (2015). Plano de contas aplicado ao setor público: desafios e benefícios. Revista Técnica CNM. Brasília: Confederação Nacional dos Municípios.

Júnior, J.J.B.S., Pereira, D.M.V.G., \& Lopes, J.E.G. (2008). Análise das habilidades cognitivas requeridas dos candidatos ao cargo de contador na Administração Pública Federal, utilizando-se indicadores. Revista de Contabilidade e Finanças, 19(46),108-121. DOI: http://dx.doi.org/10.1590/S1519-70772008000100009

Lino, A.F., \& Aquino, A.C.B. (2018). A diversidade dos Tribunais de Contas regionais na auditoria de governos. Revista de Contabilidade \& Finanças, 29(76),26-40. DOI: https://doi.org/10.1590/1808-057x201803640

Lino, A.F., Carvalho, L.B. de, Aquino, A.C.B., \& Azevedo, R.R. (2019). A falta de trabalho institucional e mudanças organizacionais incompletas em municípios brasileiros. Revista de Administração Pública, 53(2), 375-391. DOI: http://dx.doi.org/10.1590/0034-761220170404

Lopez, F.G., Bugarin, M., \& Bugarin, K. (2015). Mudanças político-partidárias e rotatividade dos cargos de confiança (1999-2013). In: Lopes, F.G.(Ed.), Cargos de confiança no presidencialismo de coalização brasileiro (pp.33-70). Brasília: IPEA.

Meier, K.J., \& Hicklin, A. (2008). Employee turnover and organizational performance: Testing a hypothesis from classical public administration. Journal of Public Administration Research and Theory, 18(4),573-590. DOI: https://doi.org/10.1093/jopart/mum028

Nogueira, F.A. (2006). Continuidade e Descontinuidade Administrativa em Governos Locais: Fatores que sustentam a ação pública ao longo dos anos. Dissertação de Mestrado. São Paulo: Fundação Getúlio Vargas.

Oliver, C. (1991). Strategic Responses to Institutional Processes. Academy of Management Review, 16(1),145179. DOI: https://www.jstor.org/stable/258610

Oliver, C. (1992). The Antecedents of Deinstitutionalization. Organization Studies, 13(14),563-588. DOI: https:// doi.org/10.1177/017084069201300403

Oliver, C. (1997). Sustainable Competitive Advantage: Combining Institutional and Resource-Based Views. Strategic Management Journal, 18(9),697-713. DOI: https://doi.org/10.1002/(SICI)10970266(199710)18:9<697::AID-SMJ909>3.0.CO;2-C

Price, J.L. (1977). The Study of Turnover. Iowa: Iowa State University Press. 
Ravanello, M., Marcuzzo, J. L., \& Frey, M. R. (2015). Análise da adequação dos municípios às normas brasileiras de contabilidade aplicadas ao setor público. Revista do CEPE, 42, 114-131. DOI: http://dx.doi.org/10.17058/ cepe.v0i42.4818

Sasso, M. (2017). Adoção das normas de contabilidade oriundas do processo de convergência às IPSAS: respostas estratégicas de governos estaduais. Dissertação de Mestrado. Universidade de São Paulo.

Schedler, A., \& Santiso, J. (1998). Democracy and Time: An Invitation. International Political Science Review, 19(1),5-18.

Spink, P. (1987). Continuidade e descontinuidade em organizações públicas: um paradoxo democrático. Cadernos FUNDAP, 7(13),57-65.

STN.(2018). Manual de Contabilidade Aplicada ao Setor Público. $8^{a}$ edição. Disponível em: <http://www.tesouro. fazenda.gov.br/mcasp>. Acesso em dez/2018.

Suddaby, R., \& Greenwood, R. (2009). Methodological issues in researching institutional change. The Sage Handbook of Organizational Research Methods, 176-195.

Tolbert, P.S., \& Zucker, L.G. (1983). Institutional Sources of in the Formal Change Structure of Organizations: The Diffusion of Civil Service Reform, 1880-1935. Administrative Science Quarterly, 28(1),22-39. DOI: https:// www.jstor.org/stable/2392383

Zonatto, V.S. (2011). Fatores determinantes para a adoção de padrões internacionais de contabilidade no Brasil: uma investigação em empresas públicas e privadas do setor de energia. Revista de Contabilidade e Organizações, 5(12),26-47. DOI: https://doi.org/10.11606/rco.v5i12.34793

\section{Como citar este artigo}

Azevedo, R. R. de; Lino, A. F. \& Diniz, J. A. (2019). Efeitos da rotatividade de pessoal sobre práticas das equipes de contabilidade em municípios. Revista de Contabilidade e Organizações, 13:e144691. DOI: http://dx.doi.org/10.11606/issn.1982-6486.rco.2019.144691 